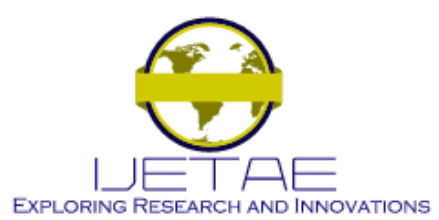

International Journal of Emerging Technology and Advanced Engineering

Website: www.ijetae.com (ISSN 2250-2459, ISO 9001:2008 Certified Journal, Volume 10, Issue 08, August 2020)

\title{
Use of Satellite Microwave Radiometric Measurements for the Analysis of Atmospheric Moisture Dynamics under the Evolution of Tropical Hurricanes
}

\author{
P. D. Alexander G. Grankov ${ }^{1}$, Alexander A. Milshin ${ }^{2}$, Dr. Evgenii P. Novichikhin ${ }^{3}$ \\ ${ }^{1}$ Leading Sci., ${ }^{2,3}$ Senior Sci., Kotel nikov Institute of Radioengineering \&Electronics, RAS, Fryazino, Russia
}

\begin{abstract}
Examples of using the data of passive microwave radiometric measurements from satellites for the analysis of atmospheric moisture dynamics are presented to display their relationship to the evolution and propagation of tropical hurricanes. The role of atmospheric water vapour as a quantitative indicator of these processes is illustrated.
\end{abstract}

Keywords - Brightness Temperature, Passive Microwave Radiometry, Tropical Hurricanes, Water Vapor of the Atmosphere.

\section{PAPER CONTENT}

Several possibilities of using satellite microwave $(\mathrm{MCW})$ radiometric systems for studying atmospheric total (columnar) water vapour evolutions in areas of tropical hurricanes $(\mathrm{TH})$ are considered in this work.

The data presented illustrate the role of atmospheric water vapour as a quantitative indicator of the evolution of tropical formations in the early stages (tropical depressions and storms), the spatial and temporal dynamics of the $\mathrm{TH}$ propagation in the ocean and their transformation.

The sources of information regarding the system oceanatmosphere (SOA) MCW radiative characteristics at the centimetre and millimetre ranges of wavelengths are the data of long-term measurements from a 7-channel 4frequency radiometer SSM/I (Scanning Sensor Microwave Imager) of meteorological satellites DMSP [1] and a 12channel 6-frequency radiometer AMSR-E (Advanced Microwave Scanning Radiometer) of an oceanographic satellite EOS Aqua [2], providing a global survey of the Earth every three day and an incomplete survey once per day.

We used the advanced global satellite archives of the oceanic and atmospheric data:
- NSIDC (National Snow \& Ice Data Center) - daily brightness temperatures from the EOS Aqua AMSR-E radiometer measured over the World Ocean, as well as products of their processing in the form of geophysical parameters mapped to a $0.25^{\circ}$ grid (submission format Gridded);

- HURSAT NCDC (National Climatic Data Center) - daily brightness temperatures from the DMSP SSM/I radiometers centred on tropical cyclones from around the globe at a $0.07^{\circ}$ latitude/longitude grid (submission format Gridded).

In addition, the synoptic histories of a number of the most intensive hurricanes reaching categories 4 and 5 in strength (on the Saffir-Simpson Hurricane Scale) were involved to provide a clear notion regarding the dynamics of meteorological and MCW radiative characteristics of the atmosphere at various stages of hurricane development.

The results started in $2008^{\text {th }}$ researches in the Institute of Radioengineering and Electronics RAS in a frame of the ISTC grant "Elaboration of technologies for diagnosis of tropical hurricanes beginning in oceans with remote sensing methods" $[3,4]$ encouraged this study.

\section{PhysiCAL BACKGROUND For ANALYSIS OF CYCLONIC PRocesses With Data OF SATEllite MCW RADIOMETRIC MEASUREMENTS}

We use the plane-layer model of natural MCW radiation $[5,6]$. In terms of this model under observations from altitude $H$ in nadir, the SOA brightness temperature $T^{\mathrm{b}}$ is the sum of three components:

$$
T^{\mathrm{b}}=T_{1}^{\mathrm{b}}+T_{2}^{\mathrm{b}}+T_{3}^{\mathrm{b}},
$$




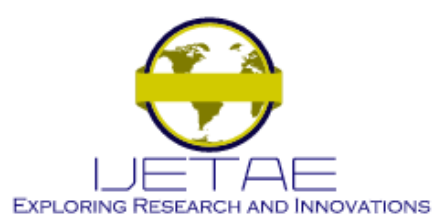

International Journal of Emerging Technology and Advanced Engineering

Website: www.ijetae.com (ISSN 2250-2459, ISO 9001:2008 Certified Journal, Volume 10, Issue 08, August 2020)

where $T_{1}^{\mathrm{b}}=T_{\mathrm{S}}^{\mathrm{b}} \exp (-\tau)$ is the brightness temperature of the ocean surface radiation $T_{\mathrm{S}}$ attenuated in the atmosphere, the quantity $T_{\mathrm{S}}$ is proportional to emissivity of the water surface $x$ and its thermodynamic temperature $T_{\mathrm{S}}\left(T^{\mathrm{b}}{ }_{\mathrm{S}}=x\right.$ $\left.T_{\mathrm{S}}\right) ; T_{2}^{\mathrm{b}}=\int_{0}^{H} T_{\mathrm{a}}(h) \exp [\tau(h)-\tau(H)] d h$ is the brightness temperature of the up-going atmosphere radiation, which is computed by summing the partial radiation fluxes $T_{\mathrm{a}}(h)$ taking into account the proper attenuation values of the atmosphere layers; $T_{3}^{\mathrm{b}}=\exp [-\tau(H)] R \int_{0}^{H} T_{\mathrm{a}}(h) \exp [-$ $\tau(h)] d h$ is the brightness of the atmosphere down-going radiation reflected by the ocean surface; $T_{\mathrm{a}}(h)$ is the atmosphere thermodynamic temperature at the horizontal level $h ; \tau(h)=\int_{0}^{h} \gamma\left(h^{\prime}\right) d h^{\prime}$ is the integral attenuation of the radiation by the atmosphere, which depends on the linear absorption factor $\gamma$ and the thickness $h$ of the absorbing layer measured from the ocean surface $(h=0)$, and $R$ is the coefficient of reflection of the atmosphere down-going radiation flux from the water surface.

The model (1) is easily extended for the case of observing the ocean surface under an arbitrary angle $\theta$ with the corrective multiplier $\sec \theta$, which allows an influence of the atmosphere optical thickness on the integral attenuation $\tau$.

Emissivity $\varkappa$ and coefficient of reflection $R$ depend on the thermodynamic temperature of the ocean surface, as well as its roughness and foaming intensity related to the near-surface wind speed. The brightness temperature of the direct and reflected radiation components of the atmosphere at centimetre and millimetre waves is determined by the absorption of radio waves, the atmosphere water vapour and oxygen, which are entirely determined by the atmosphere temperature and humidity and their vertical distribution. In addition to molecular attenuation in water vapour and oxygen, the MCW propagation at centimetre and millimetre scales is also greatly affected by various hydrometeors, first of all, rain and clouds $[5,6]$.

Later, it was grounded a possibility of using the model (1) in various hydrometeorological conditions after accomplishment of numerous satellite MCW radiometric and simultaneous ground-based measurements in a wide range of variations of the near-surface wind speed, cloud liquid water and rain rate [7].
The results of a diversity of satellite and vessel studies over energy active zones of the ocean-cyclonic (storm) zones, frontal zones, zones of influence and interaction of heat and cold currents show that the atmosphere water vapour is an important attribute of the processes of heat and water exchange between the ocean surface and atmosphere. In addition, its content in the atmosphere can serve as a quantitative characteristic of their intensity and dynamics in areas of activity of tropical cyclones [8]. A changeability of this characteristic at various stages of origination, propagation and transformation of tropical formations (from the tropical depression to the tropical storm) is the focus of our study.

\section{Early-Stage Evolution Of Tropical Hurricanes}

The synoptic histories of the arise and evolution of the tropical hurricanes Charley [9] and Katrina [10] are used here as the start points.

The hurricane Charley was born near western Africa on the $4^{\text {th }}$ of August, strengthened in Caribbean Sea and Gulf of Mexico, and made landfall on the southwest coast of the Florida peninsula.

An analysis of temporal variability of atmospheric total (columnar) water vapour content at the initial stage of hurricane Charley's development was conducted. For this, its estimates derived from EOS Aqua AMSR-E radiometer in the form of daily averaged mapped to $0.25^{\circ}$ grid values extracted from the NSIDC archive. Their temporal dependencies for various points along Charley's trajectory in the Caribbean Sea at the stages of the tropical depression and tropical storm were determined (see Figs. 1, 2).

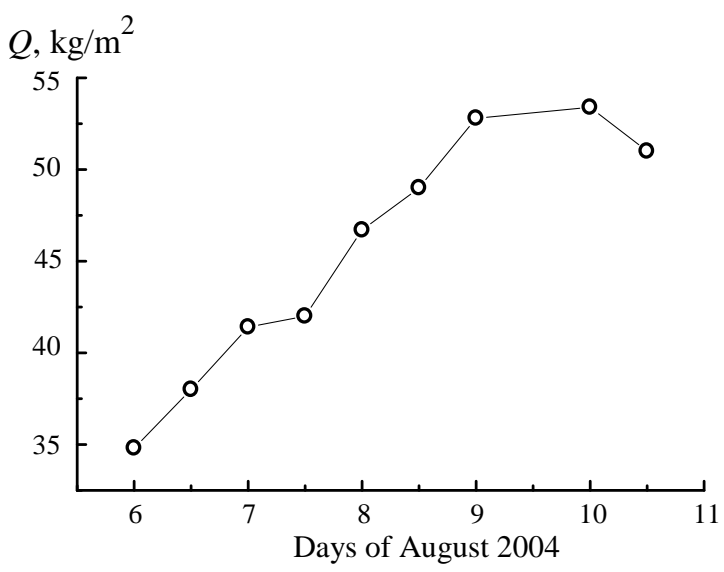

Fig. 1. Increment of the total water vapour content of the atmosphere $Q$ under evolution of hurricane Charley from the data of radiometer AMSR-E at the stage of tropical depression, in point of the hurricane trajectory $\left(12.2^{\circ} \mathrm{N} 63.2^{\circ} \mathrm{W}\right)$. 


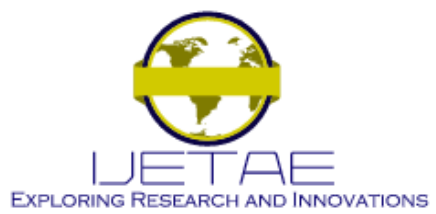

International Journal of Emerging Technology and Advanced Engineering

Website: www.ijetae.com (ISSN 2250-2459, ISO 9001:2008 Certified Journal, Volume 10, Issue 08, August 2020)

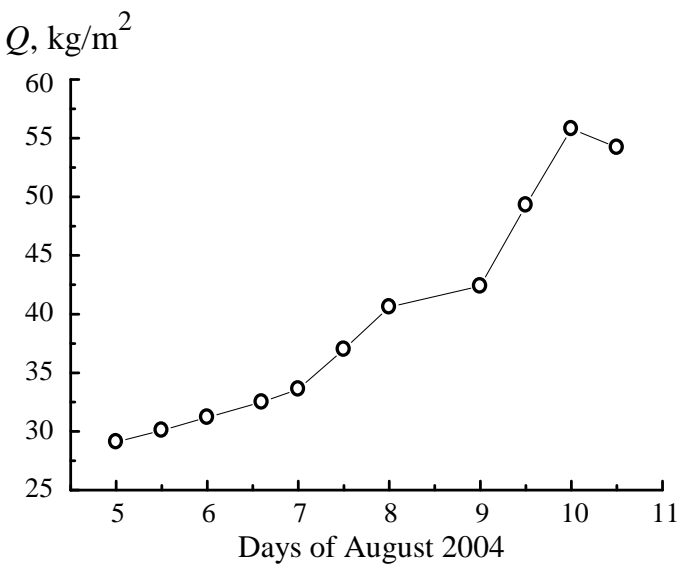

Fig. 2. Increment of the total water vapour content of the atmosphere $Q$ under evolution of hurricane Charley from the data of radiometer

AMSR-E at the stage of the sea storm, in point $\left(15.6^{\circ} \mathrm{N} 71.8^{\circ} \mathrm{W}\right)$

One can observe an increase of the atmosphere water vapour (its accumulation in the atmosphere) at each from these stages of Charley's evolution.

The brightness temperature measured from satellites in the spectral band of MCW radiation attenuation in the atmospheric water vapour (at the vicinity of the wavelength of $1.35 \mathrm{~cm}$ ) as such can be also serve as the quantitative characteristic of evolutions of the tropical formations because of their close correlation with the atmospheric moisture characteristics.

Figure 3 shows an example of the direct use of satellite measurements in this band for detecting the tropical forming Katrina at the stage of tropical depression over the south-eastern Bahamas $\left(21.5-25^{\circ} \mathrm{N}, 73.5-76^{\circ} \mathrm{W}\right.$ in August 2005).

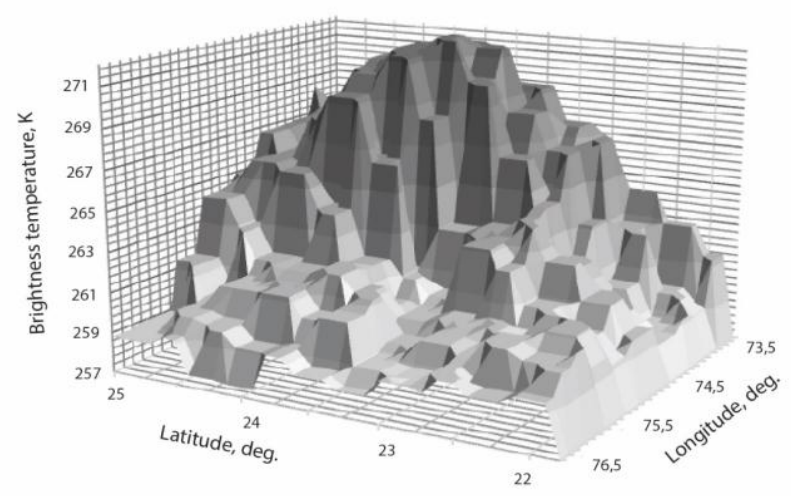

Fig. 3. Brightness temperature measured at wavelength $1.35 \mathrm{~cm}$ in the area of origin of hurricane Katrina 23 August 2005.
Brightness temperatures were measured by the SSM/I channel $22 \mathrm{~V}$ at the wavelength of $1.35 \mathrm{~cm}$ (at the frequency of $22.235 \mathrm{GHz}$ ) on vertical polarisation with radiometers SSM/I of the DMSP F13, F14, F15 satellites (archive HURSAT).

This result demonstrates a possibility of spatial localisation of the tropical forming Katrina at the stage of tropical depression with the data of measurements of the SOA brightness temperature in the resonant line of attenuation of MCW radiation in the atmospheric water vapour.

\section{PRopagation AND TRANSFormation Of Tropical HURRICANES}

Figure $4 \mathrm{~b}$ demonstrates the temporal and spatial variability of daily values of the total water vapour content in the atmosphere mapped to a $0.25^{\circ}$ grid along the trace of propagation of hurricane Wilma. This hurricane was formed in October 2005 over the Caribbean Sea, turned toward the Gulf of Mexico on $18^{\text {th }}$ October and continued its route in the Atlantic basin along the east coast of the United States (see Fig. 4a). It follows from Fig. 4 that the atmosphere water vapour can be served as the marker of propagation of hurricane Wilma along its trace.

It can be seen from Fig. 4b that the appearance of Wilma is marked by an increase of the atmosphere moisture to $35-40 \mathrm{~kg} / \mathrm{m}^{2}$ in the point 1 of the Caribbean Sea $(18$ October $00 \mathrm{~h}$ ) to $45-50 \mathrm{~kg} / \mathrm{m}^{2}$ in the point 2 of the Caribbean Sea (21 October $00 \mathrm{~h}$ ) and to $60-65 \mathrm{~kg} / \mathrm{m}^{2}$ in the point 3 of the Gulf of Mexico (24 October 00h).

Because the peak values of the atmosphere moisture correspond to the moments of passing the hurricane through one or another ocean area, we can evaluate approximately the rate of transfer of the water vapour along the trajectory of its propagation. It follows from Fig. 4, for example, that this value can be $\sim 300 \mathrm{~km}$ per day and night for hurricane Wilma at the stage of its development (18-24 ${ }^{\text {th }}$ October). 


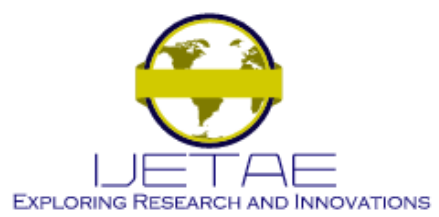

International Journal of Emerging Technology and Advanced Engineering

Website: www.ijetae.com (ISSN 2250-2459, ISO 9001:2008 Certified Journal, Volume 10, Issue 08, August 2020)

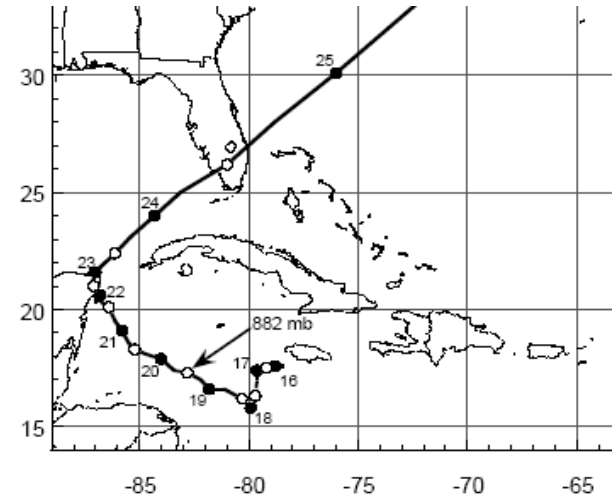

Fig. 4a. Trajectory of hurricane Wilma propagation from the area of its arising: figures are the days of October 2005 [11].
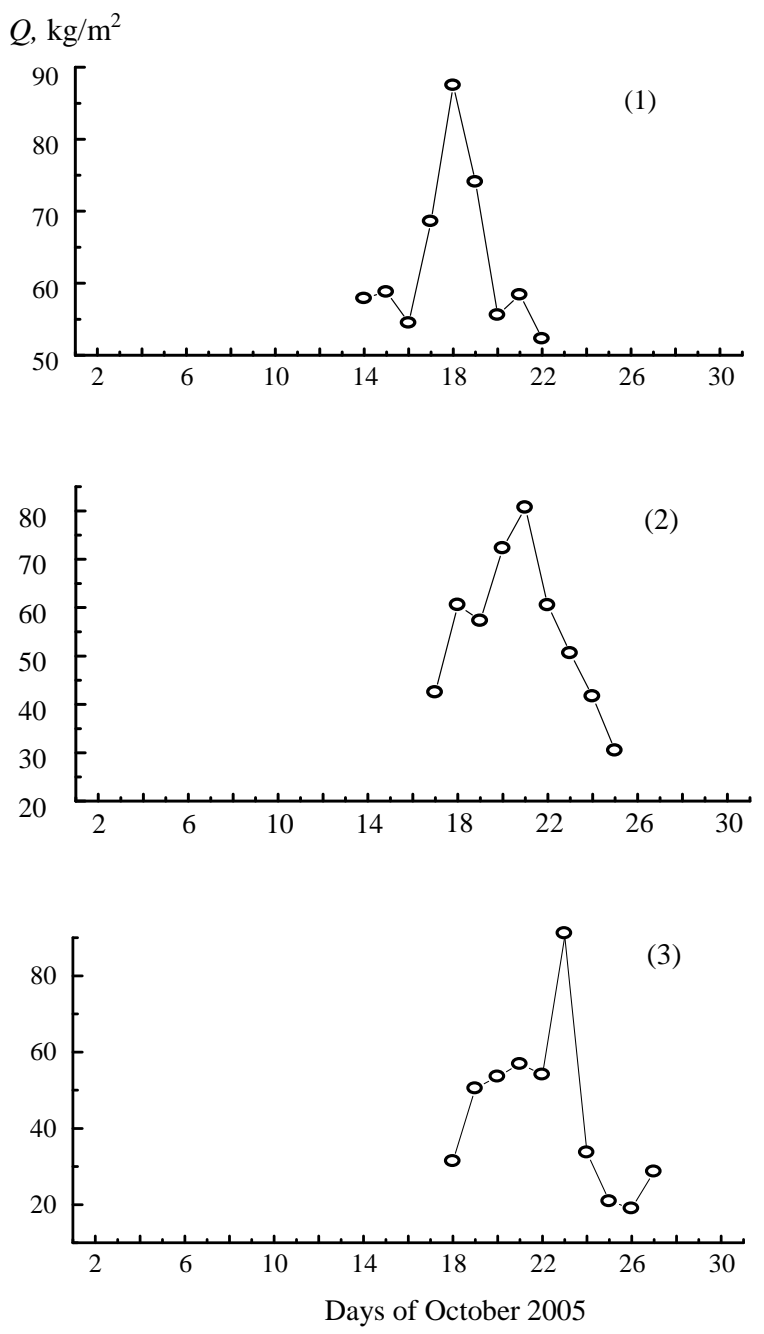

Fig. 4b. Variations of the atmosphere water vapour content derived from AMSR-E radiometer at several points of Wilma trajectory: $\left(15.8^{\circ} \mathrm{N} 79.9^{\circ} \mathrm{W}\right) ;(2)\left(19.1^{\circ} \mathrm{N} 85.8^{\circ} \mathrm{W}\right)$; (3) $\left(24^{\circ} \mathrm{N} 84.3^{\circ} \mathrm{W}\right)$.
The data on temporal and spatial variations of an intensity of SOA natural MCW radiation in the band of resonant attenuation in the atmosphere water vapour let us to evaluate not only the rate of hurricane Wilma intensification along the trace of its propagation but also the dynamics of extension of areas under its forcing.

Figure 5 illustrates a temporal and spatial variability of the brightness temperature measured by SSM/I channel $19 \mathrm{~V}$ in the form of its transversal (meridional) sections in the area of propagation of the tropical forming Wilma during the period of its origination and transformation from the stage tropical depression (15 October 2005) to a category 5 hurricane $\left(19-20^{\text {th }}\right.$ October 2015$)$. It is seen that transformation of the tropical forming Wilma from one stage to another is accomplished by increasing the brightness temperature from 20 to $50-55 \mathrm{~K}$ at the wavelength $1.55 \mathrm{~cm}$ which is sensible not only to the atmospheric moisture content but also to the near-surface wind speed. An expanding the width of $T_{19 \mathrm{~V}}^{\mathrm{b}}$ sections from 1 to $4.3^{\circ}$ (from 110 to $475 \mathrm{~km}$ ) can characterise the meridional boundaries of the hurricane propagation upon nearby water areas.

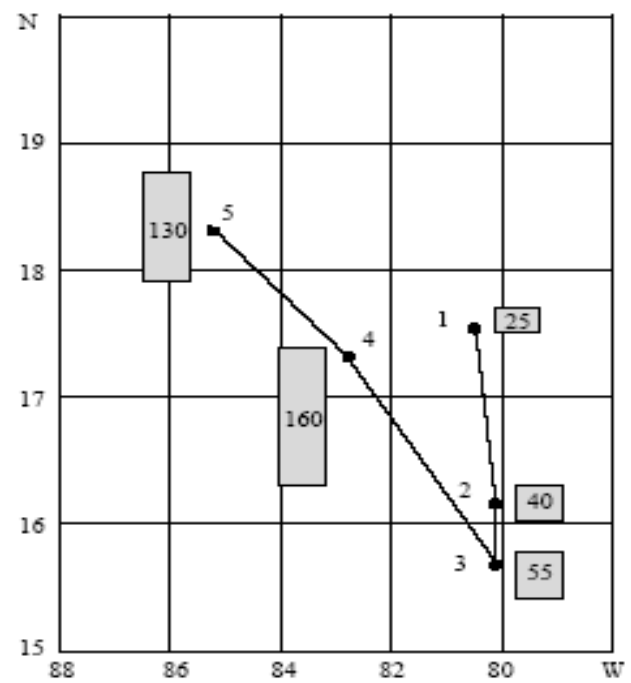

Fig. 5a. Trajectory and temporal dynamics of propagation of hurricane Wilma over the Caribbean Sea in October 2005: stages of tropical depression $(1)$; tropical storm $(2,3)$ and hurricane $(4,5)$. Figures in rectangles - wind speed in knots. 


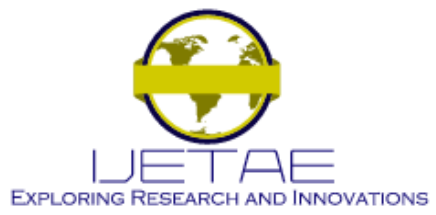

International Journal of Emerging Technology and Advanced Engineering

Website: www.ijetae.com (ISSN 2250-2459, ISO 9001:2008 Certified Journal, Volume 10, Issue 08, August 2020)

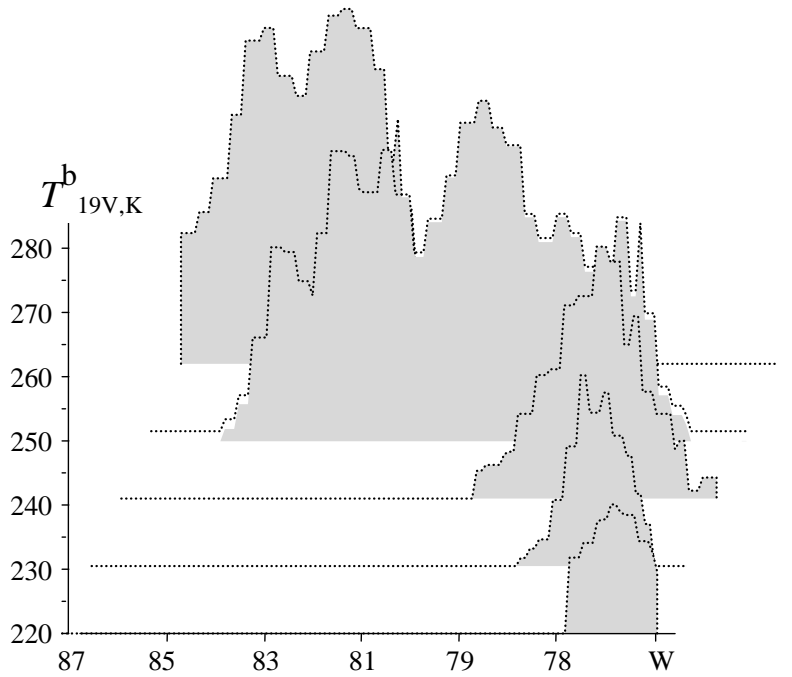

Fig. 5b. Spatial sections of the brightness temperature, measured from the SSM/I channel $19 \mathrm{~V}$ along the trajectory of propagation of the hurricane Wilma: 1 - 15 Oct., 23hh 18mm; 2 - 17 Oct. 14hh, 29mm; 3 - 18 Oct. 01h, 40mm; 4 - 19 Oct. 12hh, 14mm; 5 - 20 Oct. $12 \mathrm{hh}, 34 \mathrm{~mm}$.

\section{SUMMARY}

Satellite monitoring of the temporal and spatial changeability of the atmospheric water vapour in areas of activity of tropical hurricanes allowed us to analyse the dynamics of their strengthening during the early stages. The atmospheric water vapour can serve as a marker for determination the hurricane trajectories and boundaries of their influence on the nearby oceanic areas. We grounded the possibility of estimating the rate of transfer of the water vapour in the atmosphere along hurricanes trajectories based on the temporal and spatial dynamics of the atmosphere moisture or brightness temperature of the system ocean-atmosphere in the spectral band of its natural $\mathrm{MCW}$ radiation resonance attenuation in the atmospheric water vapour.

\section{REFERENCES}

[1] Hollinger, P.H., Peirce, J.L., and Poe, G.A. 1990. SSM/I Instrument Evaluation. IEEE Trans. Geosci. Rem. Sensing, 28 (5), 781-790.

[2] Kawanishi, T., Sezai, T., Ito, Y. et al. 2003. The Advanced Microwave Scanning Radiometer for the Earth Observing System (AMSR-E), NASDA's Contribution to the EOS for Global Energy and Water Cycle Studies. IEEE Trans. Geosci. Remote Sens., 48, 173-183, 2003.

[3] Grankov, A.G., Marechek, S.V., Milshin, A.A. et al. 2012. Elaboration of Technologies for Diagnosis of Tropical Hurricanes Beginning in Oceans with Remote Sensing Methods. In Hurricane Researches, InTech Publ. House.

[4] Grankov, A.G., ,Milshin, A.A., and Novichikhin, E.P. 2014 Behaviour of the Brightness Temperature of the Ocean-Atmosphere System under Conditions of Midlatitude and Tropical Cyclon Activity. Radiophysics and Quantum Electronics, 56 (10), 639-650.

[5] Armand, N.A. and Polyakov, V.M. 2005. Radio Propagation and Remote Sensing of the Environmental. Roca Raton, FL: CRC Press.

[6] Basharinov, A.E., Gurvich, A.S., and Egorov, S.T. 1974. Radio Emission of the Planet Earth. Nauka, Moscow: Nauka Publishers (In Russian).

[7] Wentz, F.J. 1983. A Model Function for Ocean Microwave Brightness Temperatures, J. Geophys. Res., 88 (C3), 1892-1908.

[8] Grankov, A.G. and Milshin, A.A. 2016. Microwave Radiation of the Ocean-Atmosphere: Boundary Heat and Dynamic Interaction, Second Edition, Heidelberg, Springer.

[9] Pasch, R.J, Brown, D.P., and Blake, E.S. 2004. Tropical Cyclone Report: Hurricane Charley, 9-14 August 2004, National Hurricane Center.

[10] Knabb, R.D, Rhome J.R., and Brown D.P. 2005. Tropical Cyclone Report: Hurricane Katrina 23-30 August 2005, National Hurricane Center.

[11] Pasch, J.R., Blake, E.S., Cobb III, H.D., and Roberts, D.P. 2006. Tropical Cyclone Report: Hurricane Wilma 15-25 October 2005 , National Hurricane Center. 